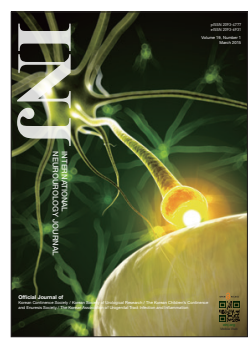

\title{
Emerging Neural Stimulation Technologies for Bladder Dysfunctions
}

\author{
Jee Woong Lee, Daejeong Kim, Sangjin Yoo, Hyungsup Lee, Gu-Haeng Lee, Yoonkey Nam \\ Department of Bio and Brain Engineering, Korea Advanced Institute of Science and Technology, Daejeon, Korea
}

In the neural engineering field, physiological dysfunctions are approached by identifying the target nerves and providing artificial stimulation to restore the function. Neural stimulation and recording technologies play a central role in this approach, and various engineering devices and stimulation techniques have become available to the medical community. For bladder control problems, electrical stimulation has been used as one of the treatments, while only a few emerging neurotechnologies have been used to tackle these problems. In this review, we introduce some recent developments in neural stimulation technologies including microelectrode array, closed-loop neural stimulation, optical stimulation, and ultrasound stimulation.

Keywords: Urinary Bladder; Microelectrodes; Electric stimulation

- Grant Support: This study was supported by Mid-career Researcher Program through National Research Foundation grant (NRF2012R1A2A1A01007327) funded by the Ministry of Science, ICT and Future Planning.

- Conflict of Interest: No potential conflict of interest relevant to this article was reported.

\section{INTRODUCTION}

The bladder is an important organ required in our daily life, and its functions are maintained by highly coordinated activities of several parts of the nervous system along with the detrusor and sphincter muscles. Information from the stretch receptors in the bladder reaches the periaqueductal gray via the spino-bulbo-spinal pathway and it is relayed to the higher brain areas. The pontine micturition center controls the bladder state between storage and voiding by communicating with other brain regions including the medial prefrontal cortex, hypothalamus, and periaqueductal gray (Fig. 1). During the bladder filling state, the detrusor muscle is relaxed and the external urethral muscle is contracted. There are three major actuator muscles in the bladder control system: the detrusor smooth muscle in the bladder wall, internal urethral sphincter located at the bladder neck, and external urethral sphincter (EUS). Control commands coordinating these actuators are mediated through hypogastric nerves, pelvic nerves, and pudendal nerves. The neurotransmitters, noradrenaline and acetylcholine, and $\beta 3$ adrenergic receptor, $\alpha 1$-adrenergic receptor, nicotinic acetylcholine receptor, and M3 muscarinic receptors are involved in contracting or relaxing the muscles. Nonneuronal cells also play a part in bladder sensory mechanisms. Urothelium responds to the chemical and mechanical stimuli and releases adenosine triphosphate, acetylcholine, and nitric oxide, which in turn modulate neural activity. Receptors for nicotinic, muscarinic, tachykinin, adrenergic, bradykinin, and transient receptor potential vanilloid type 1 have been reported in the urothelium [1-4].
Corresponding author: Yoonkey Nam (iD http://orcid.org/0000-0003-4801-9547 Department of Bio and Brain Engineering, Korea Advanced Institute of Science and Technology, 291 Daehak-ro, Yuseong-gu, Daejeon 305-338, Korea E-mail: ynam@kaist.ac.kr / Tel: +82-42-350-4322 / Fax: +82-42-350-4310 Submitted: March 9, 2015 / Accepted after revision: March 10, 2015
This is an Open Access article distributed under the terms of the Creative Commons Attribution Non-Commercial License (http://creativeenses/by-nc/3.0/) which permits unrestricted non-commercial use, distribution, and reproduction in any medium, provided the original work is properly cited. 


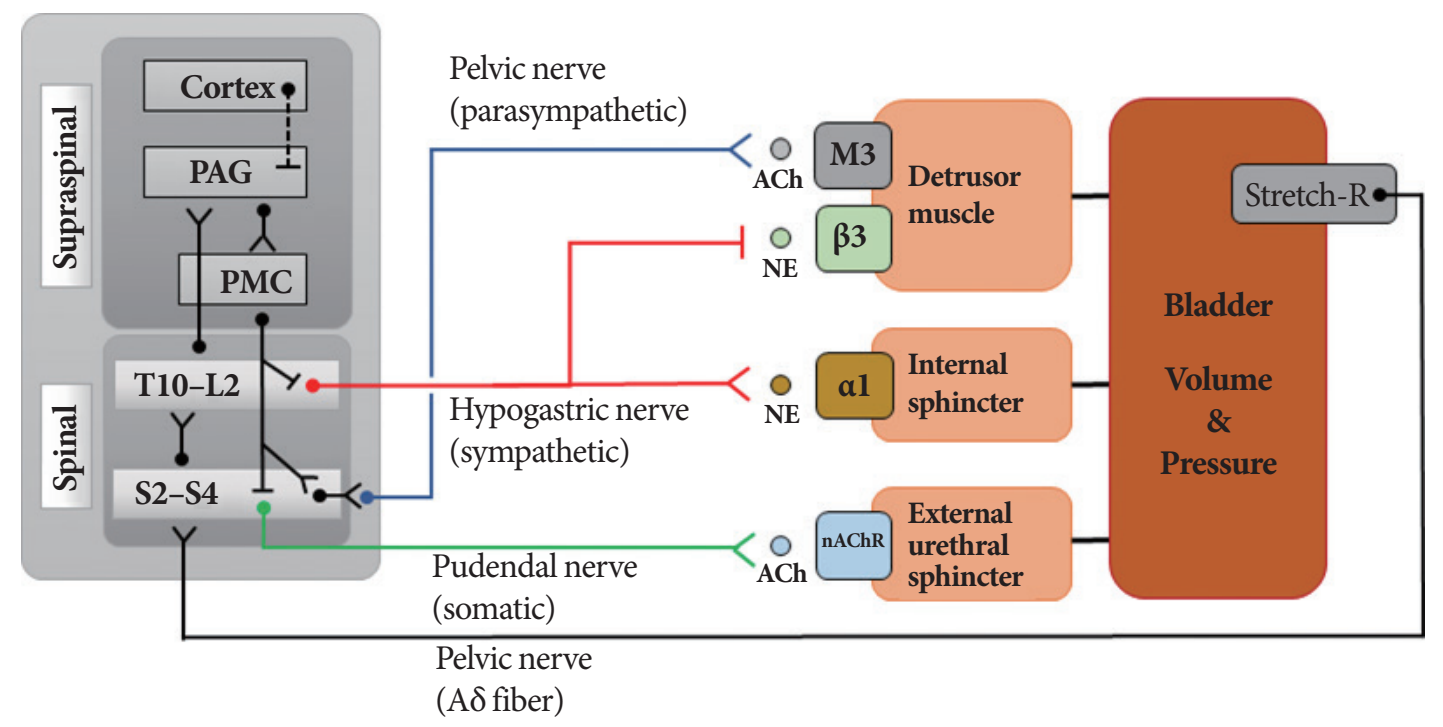

Fig. 1. Functional block diagram of the bladder control system. PAG, periaqueductal gray; PMC, pontine micturition center; ACh, acetylcholine; NE, norepinephrine; $\mathrm{nAChR}$, nicotinic acetylcholine receptor.

Loss of coordination results in neurogenic bladder dysfunctions that include overactive bladder, incontinence, obstruction of the urinary tract, or urinary retention. Treatment methods include behavioral modification, pharmacological treatment, electrical stimulation, and surgical interventions. Behavioral modifications include exercise, timed bladder voiding, bladder training, and biofeedback. For pharmacological treatments, muscarinic or adrenergic receptors are targeted using specific agonists or antagonists [5]. Electrical stimulation therapy is used with pharmacological treatments to improve the therapeutic effect. Despite the severe invasiveness, sacral neuromodulation is available for patients with intractable overactive bladder or neurogenic bladder. In this mini-review, we will introduce the neural stimulation techniques that are either used in bladder control studies or potentially applicable for bladder dysfunctions.

\section{ELECTRICAL STIMULATION OF PERIPHERAL NERVES FOR BLADDER CONTROL}

As there are many nerves involved in the bladder control system, neurogenic dysfunctions can be treated by electrical stimulation. Both invasive and noninvasive electrodes are used to modulate neural activity at the pudendal, sacral, and dorsal genital nerves for the treatment of patients with overactive bladder, urinary incontinence, and urinary retention. The control parameters for the electrical stimulation are electrical pulse shape, amplitude, pulse width, frequency, and stimulation duration. Both the inhibition and enhancement of detrusor or urinary sphincter contraction can be achieved, which leads to the relief of urinary retention and involuntary micturition.

There have been efforts to develop a reliable stimulus strategy to induce specific lower urinary track activity using electrical stimulation. The stimulation frequency and target locations are considered important in modulating the bladder activity. Low frequency stimulation current to the afferent pudendal nerve initiated reflex bladder contraction and voiding [6], while highfrequency blocking current to the efferent pudendal nerve suppressed EUS contractions, and in turn decreased intraurethral pressure [7]. In another study, low frequency stimulation to motor related fibers innervating the EUS induced sphincter closure, while high frequency stimulation to sensory related fibers inhibited bladder contractions in acute feline models [8]. Here, they used Utah Slanted Microelectrode Arrays (48 electrodes, $200 \mu \mathrm{m}$ ) intrafascicularly implanted into the pudendal nerve trunk. Similarly, bimodal bladder control (voiding or storage) was achieved using different frequencies $(30 \mathrm{~Hz}$ or 20 $\mathrm{kHz}$ ) on the lumbar ventral roots of rats [9]. Surface electrodes, which were attached to the skin, close to the pudendal nerve in felines, were used to deliver a stimulus between 5 and $7 \mathrm{~Hz}$ resulting in suppressed bladder contractions, while $20 \mathrm{~Hz}$ had both weak inhibitory and excitatory effects on the bladder contractions depending on the bladder volume [10]. Bruns et al. [11] performed intraurethral stimulation with wire electrode with 
different types of stimulus patterns (bursting or continuous) and reported that the lower frequency burst-patterns $(2 \mathrm{~Hz})$ evoked greater voiding efficiencies than lower $(<5 \mathrm{~Hz})$ or higher $(>20$ $\mathrm{Hz}$ ) continuous stimuli in a cat model. Frequency dependent modulation technique was also implemented in a closed loop stimulation study. Serial cystometries were performed in patients with spinal cord injury using low frequency $(10$ or $15 \mathrm{~Hz})$ with a surface electrode patch placed over the genital branches of the pudendal nerve, which resulted in increasing the bladder capacity from 149 to $211 \mathrm{~mL}$, while conditional stimulation outperformed continuous stimulation in reducing stimulation time from 469 to 174 seconds with increased bladder capacity of 223 $\mathrm{mL}$ [12]. In contrast to the conventional approaches, deep brain stimulation (DBS) of the pontine micturition center with frequencies ranging from $64-256 \mathrm{~Hz}$ with 1 - to $10-\mathrm{mA}$ current intensity was reported to induce increased detrusor pressure [13]. It is also reported that chronic stimulation could induce habituation of targeted nerves and degrade stimulus efficacy [14].

\section{MICROBIOSENSORS AND MICROELECTRODE ARRAY TECHNOLOGY}

In order to obtain reliable and accurate information about the state of bladder fullness, various types of sensors are needed. With the advances in nano- and microtechnologies, sensors are getting smaller and more sensitive while integrating multifunctional sensing units. Moreover, flexible substrates that can make strong adhesive and conformal contact with the skin or tissues have been developed. Using this new technology, one can measure not only the physical information (volume or pressure) and bladder activity, but also biological signals related to the muscles and nerves. Multiple types of sensors including strain gauge, thermometer, electromyography sensor, and $\mathrm{pH}$ sensor were integrated on flexible substrates [15-17], which could be further integrated into an existing medical device such as a catheter [18]. Pang et al. [19] reported a flexible and highly sensitive sensor that consists of a reversible interlocking of platinum-coated polymeric nanofibers (density: $\sim 1.85 \times 10^{9} \mathrm{~cm}^{-2}$ ) supported on polydimethylsiloxane layers with a thickness less than $500 \mu \mathrm{m}$. This study showed the gauge factor, which is the relative resistance change divided by the applied strain, to be less than 11.45 for pressure, 0.75 for shear, and 8.53 for torsion. Recently, Xu et al. [17] reported deformable arrays of sensors that can be designed to establish conformal interfaces with specific organs (heart in this study) via the use of 3-dimensional printing, thus enabling the measurement of mechanical strain using the Si-strain gauge sensors. Roger's group also developed an ultrathin sensor with bioresorbable silk fibroin substrate, which is water soluble, and they demonstrated conformal wrapping on the curvilinear cortex to measure evoked brain activity by visual stimulus in cats [20]. Electroneurogram is used to assess the dynamic bladder states by measuring the innervating nerve activity in the bladder muscles or the activity of the neuronal somata in the dorsal root ganglia (DRG). Cuff electrodes have been conventionally used to record the activity of bladder afferent nerve signals, but they present the drawback of low signal-to-noise ratios and interference from nonbladder activity. Microelectrode arrays have also been used for selective recording from nerve fibers and DRG $[21,22]$. High-density microelectrode arrays composed of 50- $\mu \mathrm{m}$-sized wired microelectrodes arranged in a 5 by 10 grid with a $200-\mu \mathrm{m}$ spacing between the electrodes provide high quality recordings of a signal unit activity from a large population of DRG neurons, making it possible to harness major afferent signals from the bladder. Bruns et al. [22] implanted a microelectrode array, which had 90 microelectrodes with an interelectrode spacing of $400 \mu \mathrm{m}$ and a shaft length of $1 \mathrm{~mm}$, into the S1 and S2 DRGs and identified 48 units (or cells) that were correlated to bladder pressure and 274 units that responded to perineal stimuli. Although microelectrode arrays were mainly used to map neural activity, it was also shown that high-density electrode arrays (25 electrodes $/ \mathrm{mm}^{2}$ ) could be used as stimulation electrodes to restore urinary function [8].

In recent studies, a flexible microchannel electrode array was developed to enhance the signal to noise ratio and to record parameters of bladder control in a spatially selective manner. The device was fabricated through a combination of photolithography and soft-lithography, and a biocompatible silicone rubber, polydimethylsiloxane, was used as a flexible substrate. The device had 5-mm-long microchannels with a cross-sectional area of $100 \mu \mathrm{m} \times 100 \mu \mathrm{m}$, and each channel had a tripolar electrode with a size of $100 \mu \mathrm{m} \times 200 \mu \mathrm{m}$ [23]. In this study, the array was implanted in the dorsal roots of S1-S2 in a rat, and large neural signal recordings $(\sim 410 \mu \mathrm{V})$ and excellent signal-to-noise ratio $(\sim 17: 1)$ were achieved. Moreover, the same group also applied this new device to design a long-term closed-loop control system, and they demonstrated that the activity of spikes had high correlation with bladder pressure and that the teased dorsal rootlets within the microchannels survived for up to 3 months [9]. 


\section{CLOSED-LOOP STIMULATION AND CONTROL SYSTEM}

Closed-loop feedback control has been adopted in many fields of neural engineering to restore neural functions. Overall, the system is composed of several imperative elements: sensors, actuators, and control units. It requires the acquisition of neural information through biosensors (e.g., microelectrodes or surface electrodes) and implementation of data processing and analyses using various types of computers (Fig. 2). Finally, a neural stimulation unit needs to be implanted at the target area to produce the desired outcome. This approach has been mainly applied for treating neurological disorders (e.g., Parkinson diseases, epilepsy) or patients who are paralyzed [24].

In epilepsy treatments, neural activity is continuously monitored by neurosensors such as microelectrode arrays to estimate the emergence of epileptic activity. The main goal is to stimulate or inhibit specific parts of the brain region to suppress the epileptic activity so that the patients can perform their daily activities without interruption. Recently, an implantable closed-loop stimulation system was approved by the U.S. Food and Drug Administration and became available for clinical use (responsive neurostimulator system, NeuroPace Inc., Mountain View, CA, USA). The whole system is packaged in a stand-alone pocket-sized unit that contains two electrodes, a battery, and a computer controller. Disc-shaped subdural electrodes (3.175- $\mathrm{mm}$ size, 10-mm spacing) are placed on the surface of the brain, and a cylindrical depth electrode (either 3.0- or 10-mm spacing) is placed in the target brain tissue. A noninvasive stimulation technique was also investigated as an alternative method for the closed-loop system approach. In the study using a rat model, the duration of epileptic activity could be suppressed by more than $60 \%$ by applying transcranial electrical stimulation triggered by the seizure detected from the cortical layers by using ten tripolar electrodes ( $50 \mu \mathrm{m}$, tungsten). Conductive stimulation pads were attached on the skull above the barrel cortex generating 50-ms Gaussian voltage waveform only when the two measured current source density spikes crossed the threshold of $1 \mathrm{mV} / \mathrm{m}$ within $200 \mathrm{~ms}$ [25].

The DBS technology still uses an 'open-loop' control system, which means that no feedback signals from the target regions (such as the thalamus, subthalamic nucleus, and globus pallidus) are provided to decide on the stimulation parameters in real time. A novel real-time adaptive DBS technique was tested in a primate model of Parkinson disease. Two separate arrays of four glass-coated tungsten microelectrodes were inserted into the primary motor cortex for the detection, and stimulating microelectrodes were placed at the globus pallidus, thus creating a feedback loop between the two brain regions. Cathodicanodic biphasic square current pulses $(80-\mu \mathrm{A}$ amplitude, 200 ms width) were used either in a pulse train mode ( 7 pulses per train, $130-\mathrm{Hz}$ intratrain frequency) or in a single pulse mode,

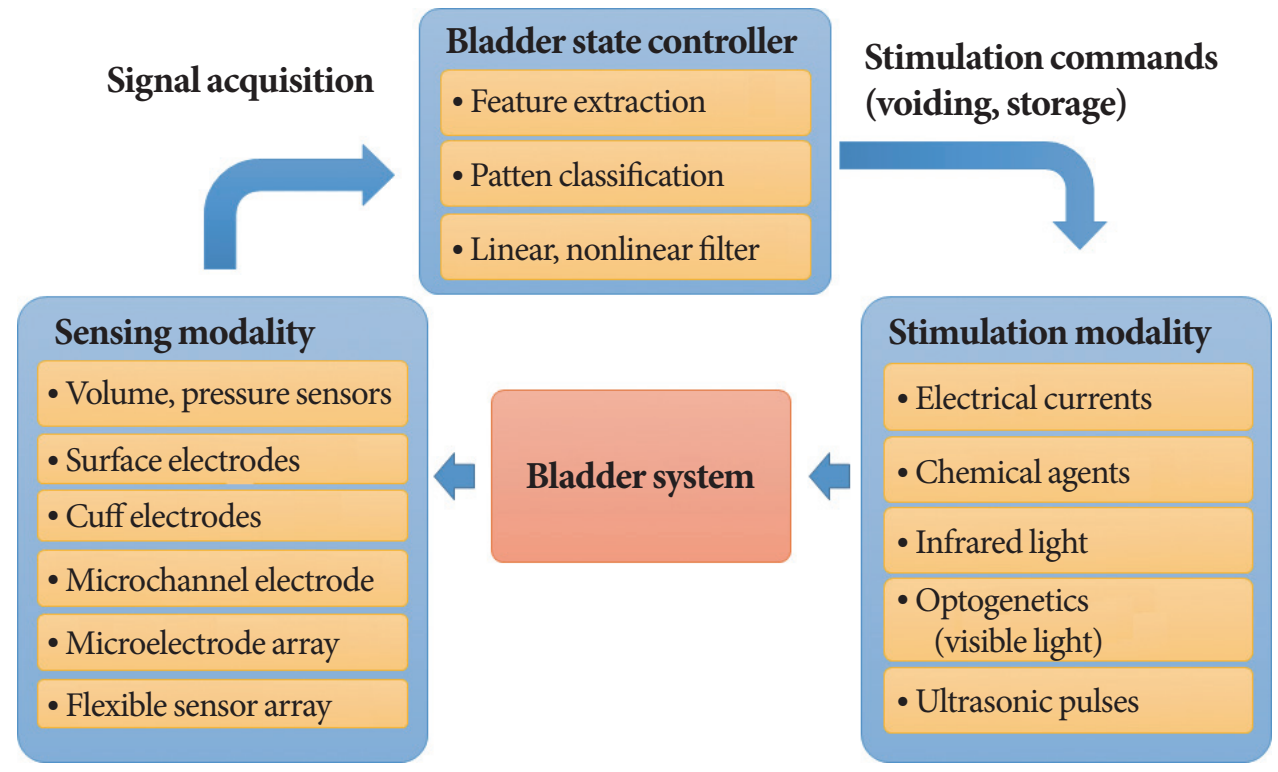

Fig. 2. Conceptual diagram of the closed-loop bladder control system with three main parts: sensing block (sensing modality), control block (bladder state controller), and stimulation block. 
and they were delivered $80 \mathrm{~ms}$ after the detection of activity from the motor cortex. The alleviation of the parkinsonian motor symptoms was compared with that observed in the case of the standard open-loop stimulation [26].

In case of patients with severe disability in motor controls, an artificial limb such as a robotic arm, is controlled by their cortical neural signals. Here, the target system is the artificial limb and the neural signals are monitored and analyzed to extract the motor command ('intention') from the patient [27]. In the study with tetraplegic patients, the motor cortex signals were decoded by the implanted microelectrode arrays, and the robotic arms were controlled by the decoded signals to perform the intended motor tasks of the patients, such as grasping and reaching $[28,29]$. In a clinical trial, an intracortical silicon microelectrode array ( $4 \mathrm{~mm} \times 4 \mathrm{~mm} \times 1.5 \mathrm{~mm}, 96$ channels) was implanted to collect neural signals, which were decoded by a linear estimator or Kalman filter to predict the patient's intention [30]. Collinger et al. [29] reported a very high success rate ( $92 \%)$ on target-based reaching tasks compared to a median chance level of $6.2 \%$.

In cases of bladder control problems, efforts have been made in several studies to monitor the bladder state and to control the time course of bladder storage and emptying, thus providing a basis for developing closed-loop bladder neuroprostheses without the need for transecting the nerves $[9,14,31]$. Wenzel et al. [14] compared conditional stimulation (closed-loop system) versus continuous stimulation (open-loop system) in the control of urinary continence. Lin et al. [31] reported that the intravesical pressure-driven closed-loop stimulation in a rat model of acute spinal cord injury resulted in increased voiding efficiency to $20 \%$ after low frequency stimulation current on the pudendal sensory nerves, which was further increased to $25 \%$ by the simultaneous delivery of low frequency stimulation current and high frequency blocking current to the sensory and motor nerves, respectively.

\section{OPTICAL STIMULATION OF NEURAL TISSUES}

\section{Optical Stimulation}

Optical stimulation of neural tissue has emerged as an important method to modulate the activity of the peripheral nerves as well as the central nerves, and has several advantages over electrical stimulation [32]. First, the precise delivery of optical energy is superior to the electrical approach. Second, it provides higher spatio-temporal resolution to stimulate individual nerves. Third, it is possible to record electrical responses from the target nerve during the stimulation, which is very difficult with electrical stimulation due to the electrical crosstalk ('stimulation artifact'). In addition, as the optical stimulation is achieved in a noncontact manner, one can minimize traumatic damage and inflammation at the interface of tissue and metal electrodes.

In general, brief pulses of infrared laser have been used as a source of optical stimulation, which is focused to a small spot on the nerve [33]. The wavelength of the infrared laser ranges from 1,400 to $2,200 \mathrm{~nm}$. In the infrared neural stimulation (INS), the rat sciatic nerve or gerbil cochlea have been commonly used as model systems, which show an excitation of evoked potentials [34-36]. Recently, INS has been applied to the central nerves such as in the motor or somatosensory cortex as well as primary neurons to initiate neural responses [37,38]. In addition to the excitation effects, the inhibition of neural firing and axonal propagation in nerves were also reported in a few studies [39-44]. Although the mechanism of neural excitation and inhibition from the INSs are not clear, it is commonly agreed that the generation of transient temperature gradient as a consequence of the heating of water by the laser would be involved in changing the neural responses $[35,45]$.

Most recently, plasmonics of nanoparticles has been utilized in the field of optical stimulation. It was demonstrated that gold nanorods (GNRs) that can convert the near infrared light (785$980 \mathrm{~nm}$ ) into heat could enhance the photothermal effect of laser, which successfully activated the neural tissues $[46,47]$. Compared to the conventional INS using longer wavelength region, the employed near infrared-sensitive GNRs was more advantageous in terms of thermal safety and tissue penetration for deeper stimulation. In contrast to the neural excitation studies, it was reported that the GNR-mediated photothermal stimulation could inhibit the electrical activity of individual neurons and neural circuits [48]. The inhibition effect was controllable by input laser power and highly reversible without thermal damages to the cells. It was further demonstrated that photothermal inhibition could be used to modulate epileptic neural activity in tissue culture models.

\section{Optogenetics}

Optogenetics combines optics (or photonics) with genetics to probe neural circuits, and light illumination is used to modulate neuronal excitation or inhibition though exogenous light-activated proteins [49]. Two genetically encoded proteins are used 
as light-gated switches: channelrhodopsin-2 (ChR2) and halorhodopsin (NpHR). ChR2 is a rapidly gated light-sensitive cation channel [50], which is derived from the microbial opsin genes [51]. NpHR is a light-driven chloride pump [52] that can silence neuronal activity through hyperpolarizing membrane potentials. The power of the optogenetic approach is that it can be engineered to selectively excite or inhibit specific cell types in the neural circuits. ChR2 and NpHR respond to different wavelengths of light, $470 \mathrm{~nm}$ and $589 \mathrm{~nm}$, respectively, which make it possible to either excite or inhibit the circuit simultaneously.

Optogenetics has been extensively applied to investigate the role of functional neural circuits related to various neurological disorders including epilepsy, depression, Parkinson disease, and other human brain disorders [53]. Krook-Magnuson et al. [54] reported the arrest of spontaneous seizures using closed-loop optogenetic system in a mouse model of temporal lobe epilepsy. They used transgenic mice expressing NpHR to directly inhibit the principal cells, and $\mathrm{ChR}$ to excite parvalbumin-expressing GABAergic neurons. Kravitz et al. [55] used transgenic mice expressing ChR2 in the regulatory elements of the dopamine D1 or D2 receptors. The study showed that the neural firing rates increased in the D1- and D2-ChR2 mice upon light stimulation, which confirmed that the activation of the direct-pathway could ameliorate motor deficits in the mouse model. Hagglund et al. [56] studied locomotion control by expressing ChR2 in glutamatergic neurons in the spinal cord. In this experiment, light stimulation of the lumbar spinal cord led to the initiation and maintenance of locomotor-like activity, which indicated that the glutamatergic neurons in the spinal cord play an important role in locomotor network.

Other than the central nervous system, optogenetics has been also applied in other organ systems. The feasibility of heart control was tested by showing heart beat control in zebrafish. Arrenberg et al. [57] made a genetically encoded zebrafish and expressed ChR2 and NpHR in the cardiac pacemaker cells in the sinoatrial (SA) node and atrioventricular node, respectively. They demonstrated that the zebrafish heart could be manipulated very precisely to rapidly switch between a healthy state and a diseased state. Illuminating the entire heart with $589 \mathrm{~nm}$ light to activate $\mathrm{NpHR}$ instantaneously blocked contractions, while periodic light illumination with $473 \mathrm{~nm}$ light to activate ChR2 in the SA ring rhythmically activated the heartbeats. In another study, researchers attempted to control insulin secretion in intact pancreatic islets [58]. They demonstrated that in- sulin secretion could be controlled through external optical stimulation mediated by ChR2-expressing pancreatic islets using a transgenic mouse model. It was successfully shown that the glucose level was controlled by light-induced insulin release in high fat diet mice.

\section{NEURAL STIMULATION USING ULTRASOUND}

Ultrasound (US) can go through solid structures like the bone and soft tissue and reach deeper from the surface. Ultrasonic stimulation has a spatial resolution in the order of a few millimeters and provides depth of 10- to $15-\mathrm{cm}$ penetration [59]. Most of all, its noninvasiveness makes it very attractive for application in human subjects. It is shown that mechanical and thermal mechanisms of US can modulate membrane potentials of neurons [60]. US has induced excitatory effects on the motor cortex and suppressive effects on the visual cortex of rabbit [61], eyeball movement through stimulating the abducens nerve in rat [62], or triggered motor behavior by stimulating the motor cortex in an intact mouse [63]. It was also shown to evoke responses from the salamander retina by activating interneurons behind the photoreceptors using focused US that has $90-\mu \mathrm{m}$ lateral resolution in vitro [64]. In human subjects, transcranial focused US was used to investigate the neuromodulation effects in the somatosensory circuits [65-67]. In addition to neural stimulation for activity control, neural regeneration effects have also been studied by determining the effects of low intensity pulsed US on cultured Schwann cells $[68,69]$, and rat nerve regeneration with poly(lactic-co-glycolic acid) conduits [70,71].

\section{CONCLUSIONS}

Advances in neural engineering for neural stimulation and recording are promising for treating disorders of the peripheral nervous system. Systematic approaches to control neural disorders have become popular, as more technologies are becoming available to the medical community. Molecular and cellular engineering approaches also have potential applications in bladder control, as there are many different types of cells involved. There are many opportunities for utilizing state-of-the-art neurotechnologies to solve bladder control issues and improve quality of life in the future. We expect that improved therapeutic effects on bladder dysfunctions can be achieved by fusing the current treatment methods with new emerging technologies. 


\section{REFERENCES}

1. Birder L, Andersson KE. Urothelial signaling. Physiol Rev 2013; 93:653-80.

2. Benarroch EE. Neural control of the bladder: recent advances and neurologic implications. Neurology 2010;75:1839-46.

3. Fowler CJ, Griffiths D, de Groat WC. The neural control of micturition. Nat Rev Neurosci 2008;9:453-66.

4. Dorsher PT, McIntosh PM. Neurogenic bladder. Adv Urol 2012; 2012:816274.

5. Abraham N, Goldman HB. An update on the pharmacotherapy for lower urinary tract dysfunction. Expert Opin Pharmacother 2015; 16:79-93.

6. Boggs JW, Wenzel BJ, Gustafson KJ, Grill WM. Spinal micturition reflex mediated by afferents in the deep perineal nerve. J Neurophysiol 2005;93:2688-97.

7. Tai C, Roppolo JR, de Groat WC. Block of external urethral sphincter contraction by high frequency electrical stimulation of pudendal nerve. J Urol 2004;172(5 Pt 1):2069-72.

8. Wark HA, Black SR, Mathews KS, Cartwright PC, Gustafson KJ, Normann RA. Restoration from acute urinary dysfunction using utah electrode arrays implanted into the feline pudendal nerve. Neuromodulation 2014 Nov 28 [Epub]. http://dx.doi.org/10.1111/ ner.12259

9. Chew DJ, Zhu L, Delivopoulos E, Minev IR, Musick KM, Mosse $\mathrm{CA}$, et al. A microchannel neuroprosthesis for bladder control after spinal cord injury in rat. Sci Transl Med 2013;5:210ra155.

10. Shen B, Roppolo JR, Subbaroyan J, Diubaldi A, Wahlgren S, de Groat WC, et al. Neuromodulation of bladder activity by stimulation of feline pudendal nerve using a transdermal amplitude modulated signal (TAMS). Neurourol Urodyn 2011;30:1686-94.

11. Bruns TM, Bhadra N, Gustafson KJ. Bursting stimulation of proximal urethral afferents improves bladder pressures and voiding. J Neural Eng 2009;6:066006.

12. Horvath EE, Yoo PB, Amundsen CL, Webster GD, Grill WM. Conditional and continuous electrical stimulation increase cystometric capacity in persons with spinal cord injury. Neurourol Urodyn 2010;29:401-7.

13. Jensen KN, Deding D, Sorensen JC, Bjarkam CR. Long-term implantation of deep brain stimulation electrodes in the pontine micturition centre of the Göttingen minipig. Acta Neurochir (Wien) 2009;151:785-94.

14. Wenzel BJ, Boggs JW, Gustafson KJ, Grill WM. Closed loop electrical control of urinary continence. J Urol 2006;175:1559-63.

15. Kim DH, Lu N, Ma R, Kim YS, Kim RH, Wang S, et al. Epidermal electronics. Science 2011;333:838-43.

16. Son D, Lee J, Qiao S, Ghaffari R, Kim J, Lee JE, et al. Multifunctional wearable devices for diagnosis and therapy of movement disorders. Nat Nanotechnol 2014;9:397-404.

17. Xu L, Gutbrod SR, Bonifas AP, Su Y, Sulkin MS, Lu N, et al. 3D multifunctional integumentary membranes for spatiotemporal cardiac measurements and stimulation across the entire epicardium. Nat Commun 2014;5:3329.

18. Kim DH, Lu N, Ghaffari R, Kim YS, Lee SP, Xu L, et al. Materials for multifunctional balloon catheters with capabilities in cardiac electrophysiological mapping and ablation therapy. Nat Mater 2011;10:316-23.

19. Pang C, Lee GY, Kim TI, Kim SM, Kim HN, Ahn SH, et al. A flexible and highly sensitive strain-gauge sensor using reversible interlocking of nanofibres. Nat Mater 2012;11:795-801.

20. Kim DH, Viventi J, Amsden JJ, Xiao J, Vigeland L, Kim YS, et al. Dissolvable films of silk fibroin for ultrathin conformal bio-integrated electronics. Nat Mater 2010;9:511-7.

21. Mathews KS, Wark HA, Warren DJ, Christensen MB, Nolta NF, Cartwright PC, et al. Acute monitoring of genitourinary function using intrafascicular electrodes: selective pudendal nerve activity corresponding to bladder filling, bladder fullness, and genital stimulation. Urology 2014;84:722-9.

22. Bruns TM, Gaunt RA, Weber DJ. Estimating bladder pressure from sacral dorsal root ganglia recordings. Conf Proc IEEE Eng Med Biol Soc 2011;2011:4239-42.

23. Delivopoulos E, Chew DJ, Minev IR, Fawcett JW, Lacour SP. Concurrent recordings of bladder afferents from multiple nerves using a microfabricated PDMS microchannel electrode array. Lab Chip 2012;12:2540-51.

24. Jackson A, Zimmermann JB. Neural interfaces for the brain and spinal cord-restoring motor function. Nat Rev Neurol 2012;8:690-9.

25. Berenyi A, Belluscio M, Mao D, Buzsaki G. Closed-loop control of epilepsy by transcranial electrical stimulation. Science 2012;337: 735-7.

26. Rosin B, Slovik M, Mitelman R, Rivlin-Etzion M, Haber SN, Israel $Z$, et al. Closed-loop deep brain stimulation is superior in ameliorating parkinsonism. Neuron 2011;72:370-84.

27. Bensmaia SJ, Miller LE. Restoring sensorimotor function through intracortical interfaces: progress and looming challenges. Nat Rev Neurosci 2014;15:313-25.

28. Hochberg LR, Bacher D, Jarosiewicz B, Masse NY, Simeral JD, Vogel J, et al. Reach and grasp by people with tetraplegia using a neurally controlled robotic arm. Nature 2012;485:372-5.

29. Collinger JL, Wodlinger B, Downey JE, Wang W, Tyler-Kabara EC, 
Weber DJ, et al. High-performance neuroprosthetic control by an individual with tetraplegia. Lancet 2013;381:557-64.

30. Wu W, Gao Y, Bienenstock E, Donoghue JP, Black MJ. Bayesian population decoding of motor cortical activity using a Kalman filter. Neural Comput 2006;18:80-118.

31. Lin YT, Lai CH, Kuo TS, Chen CC, Chen YL, Young ST, et al. Dual-channel neuromodulation of pudendal nerve with closed-loop control strategy to improve bladder functions. J Med Biol Eng 2014;34:82-9.

32. Richter CP, Matic AI, Wells JD, Jansen ED, Walsh JT Jr. Neural stimulation with optical radiation. Laser Photon Rev 2011;5:68-80.

33. Richter CP, Tan X. Photons and neurons. Hear Res 2014;311:72-88.

34. Wells J, Kao C, Jansen ED, Konrad P, Mahadevan-Jansen A. Application of infrared light for in vivo neural stimulation. J Biomed Opt 2005;10:064003.

35. Wells J, Kao C, Konrad P, Milner T, Kim J, Mahadevan-Jansen A, et al. Biophysical mechanisms of transient optical stimulation of peripheral nerve. Biophys J 2007;93:2567-80.

36. Peterson EJ, Tyler DJ. Motor neuron activation in peripheral nerves using infrared neural stimulation. J Neural Eng 2014;11:016001.

37. Cayce JM, Kao CC, Malphrus JD, Konrad PE, Mahadevan-Jansen A, Jansen ED. Infrared neural stimulation of thalamocortical brain slices. IEEE J Sel Top Quantum Electron 2010;16:565-72.

38. Cayce JM, Friedman RM, Chen G, Jansen ED, Mahadevan-Jansen A, Roe AW. Infrared neural stimulation of primary visual cortex in non-human primates. Neuroimage 2014;84:181-90.

39. Duke AR, Jenkins MW, Lu H, McManus JM, Chiel HJ, Jansen ED. Transient and selective suppression of neural activity with infrared light. Sci Rep 2013;3:2600.

40. Mou Z, Triantis IF, Woods VM, Toumazou C, Nikolic K. A simulation study of the combined thermoelectric extracellular stimulation of the sciatic nerve of the Xenopus laevis: the localized transient heat block. IEEE Trans Biomed Eng 2012;59:1758-69.

41. Cayce JM, Friedman RM, Jansen ED, Mahavaden-Jansen A, Roe AW. Pulsed infrared light alters neural activity in rat somatosensory cortex in vivo. Neuroimage 2011;57:155-66.

42. Liljemalm R, Nyberg T, von Holst H. Heating during infrared neural stimulation. Lasers Surg Med 2013;45:469-81.

43. Wu XY, Mou ZX, Hou WS, Zheng XL, Yao JP, Shang GB, et al. Irradiation of 850 -nm laser light changes the neural activities in rat primary visual cortex. Lasers Med Sci 2013;28:791-8.

44. Wang MQ, Xia QL, Wu XY, Wang X, Zheng XL, Hou WS. Optical stimulation of primary motor cortex with $980 \mathrm{~nm}$ infrared neural stimulation. Conf Proc IEEE Eng Med Biol Soc 2014;2014:6143-6.

45. Shapiro MG, Homma K, Villarreal S, Richter CP, Bezanilla F. Infra- red light excites cells by changing their electrical capacitance. Nat Commun 2012;3:736.

46. Yong J, Needham K, Brown WG, Nayagam BA, McArthur SL, Yu A, et al. Gold-nanorod-assisted near-infrared stimulation of primary auditory neurons. Adv Healthc Mater 2014;3:1862-8.

47. Eom K, Kim J, Choi JM, Kang T, Chang JW, Byun KM, et al. Enhanced infrared neural stimulation using localized surface plasmon resonance of gold nanorods. Small 2014;10:3853-7.

48. Yoo S, Hong S, Choi Y, Park JH, Nam Y. Photothermal inhibition of neural activity with near-infrared-sensitive nanotransducers. ACS Nano 2014;8:8040-9.

49. Warden MR, Cardin JA, Deisseroth K. Optical neural interfaces. Annu Rev Biomed Eng 2014;16:103-29.

50. Boyden ES, Zhang F, Bamberg E, Nagel G, Deisseroth K. Millisecond-timescale, genetically targeted optical control of neural activity. Nat Neurosci 2005;8:1263-8.

51. Nagel G, Szellas T, Huhn W, Kateriya S, Adeishvili N, Berthold P, et al. Channelrhodopsin-2, a directly light-gated cation-selective membrane channel. Proc Natl Acad Sci U S A 2003;100:13940-5.

52. Zhao S, Cunha C, Zhang F, Liu Q, Gloss B, Deisseroth K, et al. Improved expression of halorhodopsin for light-induced silencing of neuronal activity. Brain Cell Biol 2008;36:141-54.

53. Chow BY, Boyden ES. Optogenetics and translational medicine. Sci Transl Med 2013;5:177ps5.

54. Krook-Magnuson E, Armstrong C, Oijala M, Soltesz I. On-demand optogenetic control of spontaneous seizures in temporal lobe epilepsy. Nat Commun 2013;4:1376.

55. Kravitz AV, Freeze BS, Parker PR, Kay K, Thwin MT, Deisseroth K, et al. Regulation of parkinsonian motor behaviours by optogenetic control of basal ganglia circuitry. Nature 2010;466:622-6.

56. Hagglund M, Borgius L, Dougherty KJ, Kiehn O. Activation of groups of excitatory neurons in the mammalian spinal cord or hindbrain evokes locomotion. Nat Neurosci 2010;13:246-52.

57. Arrenberg AB, Stainier DY, Baier H, Huisken J. Optogenetic control of cardiac function. Science 2010;330:971-4.

58. Reinbothe TM, Safi F, Axelsson AS, Mollet IG, Rosengren AH. Optogenetic control of insulin secretion in intact pancreatic islets with $\beta$-cell-specific expression of Channelrhodopsin-2. Islets 2014;6: e28095.

59. Bystritsky A, Korb AS, Douglas PK, Cohen MS, Melega WP, Mulgaonkar AP, et al. A review of low-intensity focused ultrasound pulsation. Brain Stimul 2011;4:125-36.

60. Bachtold MR, Rinaldi PC, Jones JP, Reines F, Price LR. Focused ultrasound modifications of neural circuit activity in a mammalian brain. Ultrasound Med Biol 1998;24:557-65. 
61. Yoo SS, Bystritsky A, Lee JH, Zhang Y, Fischer K, Min BK, et al. Focused ultrasound modulates region-specific brain activity. Neuroimage 2011;56:1267-75.

62. Kim H, Taghados SJ, Fischer K, Maeng LS, Park S, Yoo SS. Noninvasive transcranial stimulation of rat abducens nerve by focused ultrasound. Ultrasound Med Biol 2012;38:1568-75.

63. Tufail Y, Matyushov A, Baldwin N, Tauchmann ML, Georges J, Yoshihiro A, et al. Transcranial pulsed ultrasound stimulates intact brain circuits. Neuron 2010;66:681-94.

64. Menz MD, Oralkan O, Khuri-Yakub PT, Baccus SA. Precise neural stimulation in the retina using focused ultrasound. J Neurosci 2013;33:4550-60.

65. Legon W, Rowlands A, Opitz A, Sato TF, Tyler WJ. Pulsed ultrasound differentially stimulates somatosensory circuits in humans as indicated by EEG and FMRI. PLoS One 2012;7:e51177.

66. Legon W, Sato TF, Opitz A, Mueller J, Barbour A, Williams A, et al. Transcranial focused ultrasound modulates the activity of primary somatosensory cortex in humans. Nat Neurosci 2014;17:322-9.
67. Lee W, Kim H, Jung Y, Song IU, Chung YA, Yoo SS. Image-guided transcranial focused ultrasound stimulates human primary somatosensory cortex. Sci Rep 2015;5:8743.

68. Tsuang YH, Liao LW, Chao YH, Sun JS, Cheng CK, Chen MH, et al. Effects of low intensity pulsed ultrasound on rat Schwann cells metabolism. Artif Organs 2011;35:373-83.

69. Zhang H, Lin X, Wan H, Li JH, Li JM. Effect of low-intensity pulsed ultrasound on the expression of neurotrophin-3 and brainderived neurotrophic factor in cultured Schwann cells. Microsurgery 2009;29:479-85.

70. Chang CJ, Hsu SH, Lin FT, Chang H, Chang CS. Low-intensity-ultrasound-accelerated nerve regeneration using cell-seeded poly (D,L-lactic acid-co-glycolic acid) conduits: an in vivo and in vitro study. J Biomed Mater Res B Appl Biomater 2005;75:99-107.

71. Park SC, Oh SH, Seo TB, Namgung U, Kim JM, Lee JH. Ultrasound-stimulated peripheral nerve regeneration within asymmetrically porous PLGA/Pluronic F127 nerve guide conduit. J Biomed Mater Res B Appl Biomater 2010;94:359-66. 